\begin{abstract}
In this paper we study the introduction of new assets which are oftenly observed to be defined in expected values rather than state by state, called the Arrow-Lind-Malinvaud (ALM) assets. We demonstrate that individual default emerges naturally in an economy where such ALM assets are introduced without completing all contingency markets. We further provide conditions under which individual default is propagated endogenously into a collective risk of widespread default in general equilibrium.
\end{abstract}

\title{
General Equilibrium with Endogenous Uncertainty and Default *
}

\author{
Graciela Chichilnisky ${ }^{\dagger}$ and Ho-Mou $\mathrm{Wu}^{\dagger \dagger}$
}

\begin{abstract}
May 2006
Keywords: Default, financial innovation, individual risk, collective risk, endogenous uncertainty
\end{abstract}

\footnotetext{
*To appear in Journal of Mathematical Economics. This paper was presented at the First Gerard Debreu Lecture given by Graciela Chichilnisky at the General Equilibrium Workshop of University of Zurich on May 21, 2005. It was first circulated at Stanford University's Stanford Institute for Theoretical Economics (SITE) as Technical Report No. 50, by Chichilnisky and Wu, dated August 1992. We are grateful to Kenneth Arrow, David Cass, Edmond Malinvaud, the anonymous referees of this journal and participants at the GE workshop of University of Zurich and the SITE Workshop at Stanford University. We are particularly grateful for support from the SITE workshop of Stanford University and from Columbia University's Program on Information and Resources (PIR) and its Consortium on Risk Management (CCRM).

$\dagger$ Columbia University,email: gc9@columbia,edu

${ }^{\dagger \dagger}$ College of Management, National Taiwan University and China Center for Economic Research (CCER), Peking University, email:homouwu@ntu.edu.tw
} 


\section{Introduction}

New financial instruments are introduced every day including indices, derivatives and innovative forms of government debt. They help manage risk and improve economic welfare. However, they can also increase macroeconomic volatility. The complexity of contractual obligation within a market can transmit individual risks and amplify them into correlated or collective risks. There are trade-offs arising from the gains and the losses created by financial innovation. This article shows the connection between financial innovation and default, and it focuses on the propagation of default in complex markets.

Markets can magnify risk. As new assets are introduced, a creditor who is a victim of default in one transaction is unable to deliver in another, thereby causing default elsewhere. In this manner default by one individual leads, through a web of obligations, to a large number of defaults. Since new instruments create new webs of obligations, financial innovation is the precipitating factor. The transmission of default from one trader to another and from one market to another transmits individual risk and magnifies it into collective risk. Default by one individual leads to a collective risk of widespread default.

We introduce a formal framework based on individual and collective risk. We show how financial instruments that are introduced to manage individual risk often increase collective risk. The newly created uncertainty does not originate in nature, but from market forces. It is endogenous uncertainty, and is best formalized by a set of simultaneous decisions that affect market behavior as in general equilibrium analysis. ${ }^{1}$

Precisely how does financial innovation lead to collective default? We start from a large economy with an incomplete set of assets, where agents face individual risks. A new asset is introduced, whose payoffs are defined in terms of expected values rather than state by state. We call these 'statistical assets'; similar assets have been studied in Arrow and Lind (1970), and Malinvaud (1972, 1973), and we denote them Arrow - Lind - Malinvaud (ALM) assets. A typical example is provided by insurance contracts, which are valued based on their expected value. Such assets exist in large societies because of the inherent difficulties of dealing with contracts whose payoffs are contingent

\footnotetext{
${ }^{1}$ The concept of endogenous uncertainty refers to uncertainty that depends on economic behavior along with nature's moves. Chichilnisky and $\mathrm{Wu}$ (1992) provided the first proof of existence of a market equilibrium with endogenous uncertainty, see also Chichilnisky and Heal (1993), Chichilnisky and Gruenwald (1995), Chichilnisky (1996, 1999). Kurz (1974) defined a research agenda of endogenous uncertainty. Recent studies on this topic include Svensson (1981), Chichilnisky, Dutta and Heal (1991), Chichilnisky (1996, 1999), Huang and $\mathrm{Wu}$ (1999), Kurz (1994, 1997), Kurz and Wu (1996), and Wu and Guo (2003, 2004).
} 
on each individual's state ${ }^{2}$, such as those in the Arrow- Debreu model. The next step is to show in Section 3 how individual default emerges with such ALM assets, and how individual default is propagated and magnified into a collective risk of widespread default once the new asset is introduced.

Since the value of a newly introduced ALM asset is determined in terms of statistics this creates states of default. For example, in Malinvaud (1972), the statistic is the expected number of people who are ill, and the random variable is the number of sick people. As the population size increases, the law of large numbers predicts that the random variable representing the number of sick people converges to a fixed proportion almost surely. Therefore in the limit, but only in the limit, insurance that is provided at actuarially fair prices - expected value - matches premium precisely to the insurance payments. However, when the economy is large but finite, no matter how close we are to the limit, the law of large numbers does not operate exactly. Therefore insurance contracts designed to deal with an exact proportion of sick people will not be able to cope with actual payments in those cases where the realized numbers exceed the limiting proportions. Insurance contracts offered at actuarially fair values (even with a premium) promise payments that exceed physical endowments, with small but positive probability. This is how default arises when ALM assets are introduced. ${ }^{3}$ Default is a typical problem in large economies with individual risks, since in such economies it is standard to use statistics to describe the characteristics of a group.

The next step is to show how individual risk, which in the limit is a statistically insignificant event, can be propagated and magnified into a major widespread default. Once default occurs the complexity of the webs of trades within the economy determines how widely it spreads, and the total amount defaulted. The main result is Proposition 1 in Section 3, which proves the existence of a general equilibrium with default when agents recontract trades in the default states. The 'default states' are collective states that are defined following the introduction of the ALM asset; each represents endogenous uncertainty, namely uncertainty that is generated by the functioning of the economy. In Section 4, we show that in an open set of economies called 'complex economies', individual default leads to a widespread default no matter how large the economy is, i.e. no matter how close we are to the limiting economy. Proposition 2 shows that in a 'robust' set

\footnotetext{
${ }^{2}$ Cass, Chichilnisky and $\mathrm{Wu}(1996)$ demonstrated that an appropriate combination of Arrow securities and mutual insurance policies can achieve efficient allocation in a world of individual and collective risks. However, in the real world there may not exist a complete set of such assets. Once we depart from the complete market economy of Cass, Chichilnisky and Wu (1996), default will occur.

${ }^{3}$ Different ways to initiate default were studied in Dubey and Geanakoplos (1989), Zame (1993) and Dubey, Geanakoplos and Shubik (2005).
} 
of large but finite complex economies, there exists a set of collective states with positive probability each, where an overwhelming majority of the households in the economy default. Following the main results we show examples of economies where the expected level of default increases with the size of each (finite) economy, although at the limit, by the law of large numbers, there is no default. Propositions 3, 4 and Example 4 in Section 5 establish that the expected value of default may exceed any bound as the population size increases, no matter how close the economy is to its limit, and that the probability of default may decrease as more financial reserves are required. An Appendix provides the mathematical proofs, and Section 6 concludes the paper.

\section{Risk: Individual and Collective, Exogenous and Endogenous}

Uncertainty is represented by random variables; each realization of the random variable is called a state. It is customary to refer to 'collective' and 'individual' risks by defining 'collective' and 'individual' states. Collective states are realizations of random variables that affect all individuals of the economy, such as an earthquake. They are described by a list of all individuals' states, which may or may not be correlated. An individual state is instead a realization of a random variable that affects one individual at the time, such as an accident or illness.

\subsection{Exogenous Individual Risk and Endogenous Col- lective Risk}

We introduce here a second classification of risk, distinguishing between exogenous states, which describe nature's moves, and endogenous states, which describe those events that depend on endogenous behavior and cannot be predicted with certainty by the agents of the economy.

Combining the two classifications we use exogenous collective states to describe moves by nature that affect all individuals in the economy. These are the only type of states considered by Arrow (1953) and Debreu (1959). Exogenous individual states are also nature's moves, but they affect only one individual at the time. These are the states considered in Arrow and Lind (1970) and Malinvaud $(1972,1973)$.

In this paper we explore an important case where individual and collective risks are simultaneously determined. The connection between individual and collective risks is mediated by economic behavior. 


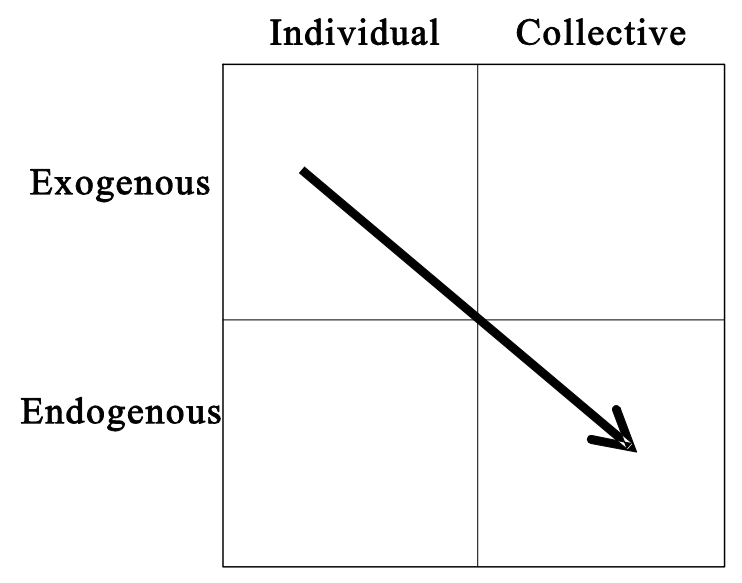

Figure 1: Classification of Risk. Assets introduced to hedge individual risk increase collective risk.

Assume that the economy is large but finite. It would be cumbersome to create contracts that depended on the states of each individual, because the lists of all individual states would be too numerous. For example in an economy with 100 individuals each of whom can be in two states (healthy or ill) a complete list of all possible states of each individual at the time contains $2^{100}$ elements (see Malinvaud $(1972,1973)$ ). Clearly, assets that promise payments contingent on such long list of states would be impractical. Therefore in large economies it is natural to observe the introduction of assets that promise payments based on statistics rather than state - by - state.

We show below that the introduction of a statistical asset of the ArrowLind-Malinvaud type lead to new states of default. Furthermore, and separately, we show later that the complexity of contractual obligations in the economy transmits and enlarges this risk into states of collective default.

In other words, we show that the introduction of certain assets to deal with individual risks increases collective risks. Although the individual risks are exogenous, depending on states of nature, the new collective risks are endogenous, depending also on economic behavior such as how many agents trade with those who defaulted. We may summarize this observation by saying that assets introduced to deal with exogenous individual risks create new endogenous collective risks. Figure 1 illustrates this observation: 


\subsection{An Economy with Individual Risk}

This section formalizes a general equilibrium economy with individual risk and default, using Malinvaud's (1972, 1973) model as a benchmark. Our economy differs from Malinvaud's in that he considers only one agent type and we consider many. In addition, we also formalize later the concept of default. First we establish the notation. Consider an exchange economy with $N$ consumption goods, indexed by $n=1, \ldots, N$ with the $N$ - th good as the numeraire $\left(p_{N}=1\right)$. There are $H$ households, divided into types indexed by $i=1, \ldots, I$, and $H_{i}$ households of type $i$, so that $H=\sum_{i} H_{i}$.

Each household faces the same set of $S$ individual states, indexed by $s=1, \ldots, S$. Let the set of collective states be denoted by $\Omega=\{\sigma: \sigma=$ $\left.\left(s^{1}, \ldots, s^{h}, \ldots, s^{H}\right), s^{h}=1, \ldots, S\right\}$, which consists of all possible lists of the individual states for the $H$ individuals, with $S^{H}$ elements. Let $s(h, \sigma)$ be the individual state given by the $h-t h$ component of the collective state $\sigma$, and $r_{i s}(\sigma)$ be the proportion of all households of type $i$ for whom $s(h, \sigma)=s$. Then $\sum_{s=1}^{S} r_{i s}(\sigma)=1$. Let $r_{i}(\sigma)=\left(r_{i 1}(\sigma), \ldots, r_{i S}(\sigma)\right)$ be the vector of these proportions of households of type $i$ among $S$ individual states for any given collective state $\sigma$. Then $r_{i}(\sigma) \in \Delta$, the $S-1$ - dimensional simplex. Similarly let $r(\sigma)$ be the proportion of households of all types for a given collective state, $r(\sigma)=\left(r_{1}(\sigma), . ., r_{I}(\sigma)\right) \in \Delta^{I}$.

Let $R_{H}$ be the set of vectors $r(\sigma)$ when $\sigma$ runs over $\Omega$, then $r(\sigma) \in$ $R_{H}$ is called an aggregate collective state because it is defined only by providing the proportions of individuals who are in each state (for each type), and does not contain any information about the identities of the individuals themselves. $R_{H}$ is contained in $\Delta^{I}$ and has $A=\Pi_{i}\left({ }_{S-1}^{H_{i}+S-1}\right)$ elements. Note that the probability $\Pi_{H}(r)$ of the aggregate collective state $r$ on $R_{H}$ can be nondegenerate and arbitrary. Let us show its property with an example in which $R_{H}$ has $H+1$ elements, and $\Pi_{H}(r)$ is defined for these $H+1$ elements.

Consider the case when there is only one type $(I=1)$. For example, when there are $S=2$ individual states, say, sick or healthy denoted by 0 or 1 , there are $2^{H}$ collective states denoted by $\sigma \in\left\{\left(s^{1}, \ldots, s^{H}\right), s^{h}=0\right.$ or $1\}$, with $H$ as the number of households in this economy. Let us be more specific and set $H=4$. Then $\sigma=(1,0,0,1)$ is an example of collective state with $r_{0}(\sigma)=\frac{1}{2}, r_{1}(\sigma)=\frac{1}{2}$ and $\sum_{i=0}^{1} r_{s}(\sigma)=1$, as described above. Hence $r(\sigma)=\left(r_{0}(\sigma), r_{1}(\sigma)\right)=\left(\frac{1}{2}, \frac{1}{2}\right) \in \Delta$. The set of aggregate collective states is represented by $R_{H}=\left\{(0,1),\left(\frac{1}{4}, \frac{3}{4}\right),\left(\frac{1}{2}, \frac{1}{2}\right),\left(\frac{3}{4}, \frac{1}{4}\right),(1,0)\right\}$, which is contained in $\Delta$. This set has $A=\left(\begin{array}{l}H+1 \\ 1\end{array}\right)=H+1=5$ elements. When the individual risk is independently distributed, we can find the corresponding probabilities of aggregate collective states: $\Pi_{H}(0,1)=\frac{1}{16}, \Pi_{H}\left(\frac{1}{4}, \frac{3}{4}\right)=\frac{1}{4}$, $\Pi_{h}\left(\frac{1}{2}, \frac{1}{2}\right)=\frac{3}{8}, \Pi_{h}\left(\frac{3}{4}, \frac{1}{4}\right)=\frac{1}{4}, \Pi_{h}(1,0)=\frac{1}{16}$. 
The definition of individual risk, as in Malinvaud (1972, 1973), does not require that the individual probabilities be identically and independently distributed (iid) random variables, although iid's certainly satisfy our definition of individual risk. The following definition allows a wide class of populations of random variables in which correlations may exist between individual's random variables, provided that as the population increases in size all collective risk disappears, or, in other words, in the limit the probability distribution over collective states is supported on a single point. Formally, the concept of individual risk means that the proportion $r_{i s}^{\infty}$ of type $i$ individuals in state $s$ (which is generally given by a set describing all collective risks) is actually a singleton with probability one in the limit. In other words, individual risk means that in the limit there is only one state of aggregate collective risk in $\Delta^{I}$ :

Definition 1: An economy is said to have individual risk if as $H \rightarrow \infty$, $\Pi_{H}(r) \rightarrow \Pi^{\infty}(r)$ where $\Pi^{\infty}(r)$ is a point distribution on $\Delta^{I}$ namely $\Pi^{\infty}$ is a degenerate distribution concentrated on one point $r^{\infty} \in \Delta^{I}, \Pi^{\infty}\left(r^{\infty}\right)=1$.

In our previous example $(I=1)$ as $H \rightarrow \infty, \Pi_{H}(r) \rightarrow \Pi^{\infty}(r)$ with $\Pi^{\infty}(r)=$ 0 for $r \neq\left(\frac{1}{2}, \frac{1}{2}\right)$. In this example, $\Pi^{\infty}(r)$ is a point distribution on $\Delta$ concentrated on $r^{\infty}=\left(\frac{1}{2}, \frac{1}{2}\right)$ and $\Pi^{\infty}\left(\frac{1}{2}, \frac{1}{2}\right)=1$. In other words, with individual risk only one aggregate collective state will occur with probability one in a large economy as $H \rightarrow \infty$.

Let $\Pi_{\sigma}$ be the probability of the collective state $\sigma$. The following anonymity assumption is required so that identities of individuals do not affect the nature of risk faced by them:

Assumption A1 (Anonymity) : $r(\sigma)=r\left(\sigma^{\prime}\right)$ implies $\Pi_{\sigma}=\Pi_{\sigma^{\prime}}$.

The von Neumann- Morgenstern utility function of household $h$ of type $i$ in terms of collective states $\sigma$ is

$$
W^{i}\left(x_{h}^{i}\right)=\sum_{\sigma} \Pi_{\sigma} U_{s(h, \sigma)}^{i}\left(x_{h \sigma}^{i}\right)
$$

where $x_{h \sigma}^{i} \in \mathbf{R}^{N+}$ is the consumption vector. All households $h$ of type $i$ have the same endowment $e_{s r}^{i}=e_{s}^{i}$ in any aggregate collective state $r$ and individual state $s$, and the same probabilities $\rho_{i s}$ for each state $s$.

In addition to A1, we also need the convexity assumption for the study of the properties of a general equilibrium:

Assumption A2 (Convexity) : Individual utility functions $U(\cdot)$ are concave.

The von Neumann - Morgenstern utility can also be written in terms of 
aggregate collective states $r$ or individual states $s$ :

$(2)$

$$
W^{i}\left(x^{i}\right)=\sum_{r \in R_{H}} \Pi(r) \sum_{s=1}^{S} r_{i s} U_{s}^{i}\left(x_{s r}^{i}\right)
$$

or

(3)

$$
W^{i}\left(x^{i}\right)=\sum_{s=1}^{S} \rho_{i s} U_{s}^{i}\left(x_{s}^{i}\right)
$$

where $x_{s}^{i} \in \mathbf{R}^{N+}$ is the consumption of a household of type $i$ in individual state $s$, as explained in the Appendix.

\section{A Market with Default}

\subsection{How does default occur?}

As already noted, in a large but finite economy, excess demand may fail to be zero at some aggregate collective states $r \in R_{H}$ with positive probabilities. This is because there are states $r$ where the traders' promises exceed physical constraints. Similarly, there are states $r$ where the insurer may fail to deliver on its promises. The purpose of this section is to formalize how defaults occur before recontracting is negotiated in a finite economy $E$.

The aggregate collective states give us all information needed to find out whether default has occurred without recontracting. For each aggregate collective state $r \in R_{H}$, households face a price vector $p_{r} \in \mathbf{R}^{N}$ and choose $x_{s r}^{i}$, the demand of households of type $i$ in the aggregate collective state $r$ and individual state $s$. It is derived from maximizing their utility function (2) over the budget set of feasible $x_{s r}^{i}$ satisfying

$$
p_{r}\left(x_{s r}^{i}-e_{s}^{i}\right)=v_{s}^{i}
$$

where $v_{s}^{i}$ is the net transfer of numeraire good from the insurance contract or the ALM asset to households of type $i$ in state $s=1, \ldots, S$.

For each price vector $p^{A}=\left(p_{r}\right)_{r \in R_{H}} \in \mathbf{R}^{N A}$, the excess demand correspondence $\xi_{s r}^{i}\left(p_{r}\right)$ has typical elements $x_{s r}^{i}-e_{s}^{i}$, and the aggregate vector of exact (actual) total excess demand is:

$$
x_{r}(p)=\sum_{i} H_{i} \sum_{s=1}^{S} r_{i s} \xi_{s r}^{i}\left(p_{r}\right),
$$


where $r_{i s}$ is the proportion of individuals of type $i$ in the individual state $s$ within the aggregate collective state $r$.

Definition 2: There is individual default in state $r$ at equilibrium prices $p$ without recontracting if some coordinate of the aggregate excess demand $\sum_{i, s} H_{i} r_{i s}\left(\xi_{s r}^{i}\left(p_{r}\right)\right)$ is strictly positive; $r$ is then called a state of individual default without recontracting.

The set of all individual default states without recontracting is denoted by $\Psi$. Specifically from now on we consider for each $r$ the difference between the receipts from insurance payments, and the total premium collected is:

$$
M(r)=\sum_{i, s} H_{i} r_{i s} v_{s}^{i}
$$

where $v_{s}^{i}$ is the transfer from the insurer to a household of type $i$ in individual state $s$. Here $M(r)$ can be considered as a deviation from Walras's Law when recontracting is not yet allowed. The insurer is a (private or public) company who is risk neutral with an initial endowment $e$, the same in all states, and a utility function $W(y)=\sum_{r} \Pi_{r} y_{r}$, where $y \in R^{N A}$ as in definition 4 below, where $W(y)$ denotes the expected return of a risk neutral insurer.

Definition 3: Any aggregate collective state $r$ with $M(r)>0$ is defined to be a state of insurance default without recontracting.

The set of insurance default states is denoted by $\Gamma$. We also write $\Gamma_{H}$ and $D_{H}$ to indicate their dependence on the population size $H$. Let $\nabla$ be the union of the sets $\Gamma$ and $\Psi$. This set is the set of all default states. In the following example we demonstrate how default occurs in an economy with ALM assets, in which $\nabla=\Gamma$.

\section{Example 1: An Economy with Default Risk}

There are $I=3$ types of households, $H$ of each, three goods, $N=3$, and two states of individual risk for each household, $S=\{1,2\}$. Assume that for each $i$ and all $s$, individual risk is defined by $\rho_{i s}=0.5$, and that individual risks are identical and independently distributed random variables. $H$ is assumed to be even so that $H / 2$ is an integer and there exist aggregate collective states with $r_{i s}=0.5$. The utilities of the agents are:

$$
W^{i}\left(x^{i}\right)=\sum_{s=1}^{2} \rho_{i s} U^{i}\left(x_{s}^{i}\right),
$$

where $U^{i}$ is state independent and Cobb - Douglas (the same for all $s$ ), $x_{s n}^{i}$ is consumption of good $n$ by the i-th type of households in state $s$ and 
$x_{s}^{i}=\left(x_{s n}^{i}\right)$. When consumption of good $m$ is state independent it is denoted $x_{m}^{i}$. Endowments of households of type 1 and 3 are state independent; they are denoted $e^{1}=(0,1,0)$ and $e^{3}=(1,0,0)$. Type 2 households have different endowments in state 2 , the unfavorable state, than in state 1 , the favorable state: $e_{2}^{2}=(0,0,0)$ and $e_{1}^{2}=(0,0,2)$. This implies that there are $2^{H}$ collective states denoted by $\sigma$ in $\Omega$ (rather than $2^{3 H}$ ), because only agents of type 2 face individual risk. There are $A=H+1$ aggregate collective states denoted by $r$ in $R$, each identified by the proportion of agents of type 2 who are in state 2 . The utilities of type $i$ households $U^{i}: R_{+}^{3} \rightarrow R$ are:

$$
\begin{gathered}
U^{1}=4 \ln x_{1}^{1}+\ln x_{2}^{1} \\
U^{2}=1 / 2\left(4 \ln \quad x_{12}^{2}+\ln x_{13}^{2}\right)+1 / 2\left(4 \ln x_{22}^{2}+\ln x_{23}^{2}\right) \\
U^{3}=4 \ln x_{3}^{3}+\ln x_{1}^{3}
\end{gathered}
$$

The market is incomplete so far because there are no assets to deal with the risk faced by the second type of household.

An ALM asset is now introduced, i.e. a set of transfers across different states with expected value equal to zero. We now compute an equilibrium of this economy, as defined above. Let $p=\left(p_{1}, p_{2}, p_{2}\right)$ and assume that good 3 is the numeraire, $p_{3}=1$. Type 2 wants to purchase insurance offered by the insurer, called agent type 0: type 2 pays $q$ units of the numeraire (good 3) in both states and receives 1 unit of good 3 in the unfavorable state $(s=2), q$ is the insurance premium for each unit of this contract. Let $\mu$ be the amount of insurance contract purchased by type 2. Both $p$ and $\mu$ are determined endogenously. The insurer, type zero, who is risk neutral has utility only for good 3, and offers an insurance contract that is actuarially fair, $i$. e. $q=\rho_{2 s}=1 / 2$, with zero expected value (either due to competition or regulatory constraint). Type 2 agents maximize their utility $U^{2}$ subject to

$$
\begin{gathered}
p_{2} x_{12}^{2}+x_{13}^{2}=2-q \mu, s=1, \\
p_{2} x_{22}^{2}+x_{23}^{2}=(1-q) \mu, s=2,
\end{gathered}
$$

obtaining

$$
\begin{aligned}
& x_{12}^{2}=(4 / 5)(2-q \mu) / p_{2} x_{13}^{2}=(1 / 5)(2-q \mu), \\
& x_{22}^{2}=(4 / 5)(1-q) \mu / p_{2} x_{23}^{2}=(1 / 5)(1-q) \mu .
\end{aligned}
$$

With actuarially fair insurance $q=1 / 2$, we obtain $\mu=2$ and the demand of type 2 household:

$$
x_{12}^{2}=x_{22}^{2}=x_{2}^{2}=(4 / 5)\left(1 / p_{2}\right)
$$




$$
x_{13}^{2}=x_{23}^{2}=x_{3}^{2}=1 / 5
$$

Furthermore, one obtains

$$
\begin{aligned}
& x_{1}^{1}=4 p_{2} / 5 p_{1}, x_{2}^{1}=1 / 5, x_{3}^{1}=0 . \\
& x_{1}^{3}=1 / 5, x_{2}^{3}=0, x_{3}^{3}=4 p_{1} / 5 p_{3} .
\end{aligned}
$$

Since type 0 (insurer) has no need to trade, there is a unique price equilibrium $p *$ :

$$
p_{1}^{*}=p_{2}^{*}=p_{3}^{*}=1 \text {. }
$$

The equilibrium consumption vectors are:

$$
x^{1 *}=(4 / 5,1 / 5,0), x^{2 *}=(0,4 / 5,1 / 5), x^{3 *}=(1 / 5,0,4 / 5)
$$

Note that the insurer collects one unit $q \mu=1$ of the numeraire good from type 2 households in state 1 and gives one unit of the numeraire good to those who are in state 2 . Once individual risk is realized, it is clear that default occurs for some aggregate collective states $\left(r>\frac{1}{2}\right)$ when those in bad state outnumber those in good state. There are more than one half of type 2 households who are in the unfavorable state; such a default state is in $\Gamma$. $\diamond$

\subsection{Default and Recontracting}

When default occurs, the actual insurance payments are assumed to be made proportionally to what is owed. Because of limited liability, individuals have to recontract to reach a new equilibrium. We consider below the framework that at each default state $d \in \nabla$, individuals recontract with each other, so that new net trades and market clearing prices emerge at each default state. The informational structure of the model is similar to that of the Arrow and Debreu model: privacy is preserved in the sense that individuals know their own endowments and preferences but not those of others. Let us understand how recontracting can reach a new equilibrium by the following example.

\section{Example 2: Default Equilibrium with Recontracting}

After the insurance contract is introduced in the economy of Example 1, and over under payment to the insuree occurs, new state contingent prices and allocations emerge. We compute these now.

The total number of aggregate states in the perfect foresight equilibrium is $V+1$, one for the no-default state and $V$ default states with $V=H / 2$ if $H$ is even and $V=(H+1) / 2$ if $H$ is odd. In terms of the notation of the last section, $\rho_{2 s}=1 / 2(s=1,2), v_{s}^{i}=-1$ if $s=1$, and $v_{s}^{i}=1$ if $s=2$ and 
type $i=2$. Note that $r \in \Gamma$ (insurance default state) if $r>1 / 2$. For $r \in \Gamma$, we demonstrate that $p_{r}^{*}$ satisfies $p_{1}^{*}=p_{2}^{*}=2(1-r), p_{3}^{*}=1$. Furthermore, default is denoted by $\delta_{s r} ; \delta_{s r}=0$ if $s=1, \delta_{s r}=-1+(1-r) / r<0$ if $s=2$.

Type 2 agents purchase full insurance as in Example 1. After the realization of individual state $(s=1,2)$ for type 2 , there are $2^{H}$ collective states and $A=H+I$ aggregate collective states, indexed by $r=0, . ., 1$, i.e. by the proportion of type 2 agents in the unfavorable state 2.

When $r>1 / 2$, and $s=2$, the adjusted payment with recontracting from the insurer is only $(1-r) / r<1$ (due to the limited liability provision). This is a default state, $r \in \Gamma$. If $s=1$, type 2 's endowment is $(0,0,1)$ for $(1-r) H$ of them; for the same case but when $s=2$, type 2's endowment is $(0,0,(1-r) / r)$ for $r H$ of them. Given these endowments, type 2 agent's maximize utility $U^{2}$ and we derive type 2's demand:

$(1-r) H$ of type 2's demand is $x_{1}^{2}=0, x_{2}^{2}=(4 / 5)\left(1 / p_{2}\right), x_{3}^{2}=1 / 5$, and excess demand is $\left(0,4 / 5 p_{2},-4 / 5\right)$. A proportion $r H$ of type 2 's demand is $x_{1}^{2}=0, x_{2}^{2}=\left(4 / 5 p_{2}\right)(1-r) / r, x_{3}^{2}=(1 / 5)(1-r) / r$, and excess demand is $\left(0,\left(4 / 5 p_{2}\right)(1-r) / r,(-4 / 5)(1-r) / r\right)$. Type 1 's excess demand is $\left(\left(4 p_{2} / 5 p_{1}\right),(-4 / 5), 0\right)$, and there is $H$ of them. Type 3 's excess demand is $\left(-(4 / 5), 0,4 p_{1} / 5 p_{3}\right)$, for $H$ of them.

Market clearing conditions are:

Good 1: $\left(4 p_{2} / 5 p_{1}\right) H-4 H / 5=0$, so $p_{1}=p_{2}$.

Good 2: $(1-r) H\left(4 / 5 p_{2}\right)+\left(4 H / 5 p_{2}\right)(1-r)-4 H / 5=0$, so $p_{2}=2(1-r)<1$.

Good 3: $(-4 / 5)(1-r) H-(4 / 5)(1-r) H+(4 / 5) p_{1} H=0$, so $p_{1}=2(1-r)<1$.

The recontracted equilibrium price vector becomes contingent on the aggregate collective state with default $(r>1 / 2)$ is $p_{1}^{*}=p_{2}^{*}=2(1-r), p_{3}=1$.

Equilibrium consumption vectors are

$x^{1}=(4 / 5,1 / 5,0)$ (same as in Example 1, not affected by default),

$x^{2}=(0,4 / 10 r,(1 / 5)(1-r) / r)$ for $r H$ of them (less consumption),

and $=(0,4 / 10(1-r), 1 / 5)$ for $(1-r) H$ of them (more consumption),

$x^{3}=(1 / 5,0,(4 / 5) 2(1-r))$ (less consumption).

Note that the market clears with recontracting: sum of all demand equals $(H, H, 2(1-r) H)$ which is the total supply of commodities and $x^{o}=$ $(0,0,0)$ for the insurer.

Next we compute the equilibrium prices for aggregate collective state without default $(r \leq 1 / 2)$ :

Now type 0 receives $(1-r) H$ of good 3 and pays out $r H$ only, so it has a surplus of $(1-2 r) H>0$ of good 3 . Since by assumption, agent 0 's utility is a function of good 3 only, all the surplus $(1-2 r) H$ is consumed directly in good 3 , and this agent's excess demand is the zero vector. 
Market clearing conditions implies that: $p_{1}^{*}=p_{2}^{*}=p_{3}^{*}=1$ (prices stay constant).

Consumption vectors are

$x^{1}=(4 / 5,1 / 5,0)$,

$x^{2}=(0,4 / 5.1 / 5)$,

$x^{3}=(1 / 5,0.4 / 5)$,

and

$x^{o}=(0,0,(1-2 r) H)$.

Note that markets clear: the sum of all demand vectors equals the total supply of commodities. To see that $\mathbf{E}$ is complex we refer to the next section. $\diamond$

There are I insurance contracts or ALM assets, $S$ - dimensional vectors of transfers $\left(v_{s}^{i}\right)$, one such vector for each type of individual, $i$. Individuals anticipate correctly that there is default in states $d \in \nabla$, and also the extent of changes $\delta_{s d}^{i}$ in their insurance payments (in the numeraire good) to the i-th type of household in individual state $s$ for default states $d$. The value of their consumption in such states does not exceed the value of their endowment plus the anticipated (reduced) insurance payments received. Then an individual's income is now contingent on the aggregate collective state of the economy, $r$. Therefore there are $A$ states ( $A$ is the cardinality of the set $R_{H}$ ) in the economy. We now have $N A$ markets with recontracting.

A price $p^{A}$ is now a vector in $\mathbf{R}^{N A}$. A consumption plan $x^{i}$ for household $h$ of type $i$ consists of SA consumption vectors in $\mathbf{R}^{N}$ denoted $x_{s r}^{i}$, one for each aggregate collective state $r \in R_{H}$, and individual state $s$. Recall that the insurance contracts provide transfers $v_{s}^{i}$, which are exogenous for the household with $\sum_{s} \rho_{i s} v_{s}^{i}=0$ in all no - default states. The data of the model, known to all the households, include now the probabilities $\Pi_{r}$ of all aggregate collective states $r \in R_{H}$, in particular those of the default states $d \in \nabla$, and also the shortfalls $\delta_{s d}^{i}<0, s=l, \ldots, S$, on the payment to the $h$ household of type $i$ at the aggregate collective state $r$. Note that with perfect foresight, the ALM asset with payoff vector $\left(v_{1}^{i}, \ldots, v_{S}^{i}\right), i=1, \ldots, I$, ceases to be a statistical asset and becomes a state contingent contract for the insured. This is because the insured is now aware of the contingent payment $v_{s}^{i}+\delta_{s d}^{i}$ in all the collective states $r$ in which there is default, $r \in \nabla$.

In order to make explicit the asset structure of the model, we define the aggregate collective states as follows:

$$
r \in \Gamma \text { (insurance default states })=\{1, \ldots, V\}
$$

and assume for simplicity in the exposition that there is one $r$ without default,

$$
r=0 \text { (the no default state) }
$$


so we can write $r=0,1, \ldots, V$, or $r \in\{0,1, . ., V\}$. The corresponding price vector is $p_{r}, r=0, \ldots, V, p_{r} \in \mathbf{R}^{N}$. The two budget constraints (7) and (8) can be written as one equation:

$$
p_{r}\left(x_{s r}^{i}-e_{s r}^{i}\right)=\delta_{s r}^{i}+v_{s}^{i}, r=0,1, \ldots V, s=1, \ldots, S,
$$

where $\delta_{s 0}^{i}=0$, (i.e.when $\left.r=0\right), x_{s r}^{i} \in \mathbf{R}^{N}, e_{s}^{i} \in \mathbf{R}^{N}, p_{r} \in \mathbf{R}^{N}, \delta_{s r}^{i}$ and $v_{s}^{i}$ are scalars. The " $\square$ " operation " $\square$ " is defined in a standard fashion:

$$
p \square\left(x_{s}^{i}-e_{s}^{i}\right)=\left[\begin{array}{l}
p_{o} \cdot\left(x_{s o}^{i}-e_{s}^{i}\right) \\
\cdots \\
p_{r} \cdot\left(x_{s r}^{i}-e_{s}^{i}\right) \\
\cdots \\
p_{V} \cdot\left(x_{s V}^{i}-e_{s}^{i}\right)
\end{array}\right]
$$

for a given $s$, where the right hand side of $(15)$ is an $(V+1) \times 1$ matrix. Then equation (14) can be written:

$$
p \square\left(x_{s}^{i}-e_{s}^{i}\right)=X_{s}^{i}=\left[\begin{array}{l}
v_{s}^{i}+0 \\
\cdots \\
v_{s}^{i}+\delta_{s r}^{i} \\
\cdots \\
v_{s}^{i}+\delta_{s V}^{i}
\end{array}\right]
$$

for $s=1, \ldots, S$. Let $X^{i}=\left[X_{1}^{i}, \ldots, X_{s}^{i}, \ldots, X_{S}^{i}\right]$, an $(V+1)$ x $S$ matrix, then we can write (14) more compactly as follows:

$$
\left[p \square\left(x_{1}^{i}-e_{1}^{i}\right), \ldots, p \square\left(x_{s}^{i}-e_{s}^{i}\right), \ldots, p \square\left(x_{S}^{i}-e_{S}^{i}\right)\right]=X^{i}
$$

(both are $(V+1) \times S$ matrices), where $X^{i}$ is the payoff matrix of asset $i$ :

$$
X^{i}=\left[\begin{array}{lll}
v_{1}^{i} & \ldots & v_{S}^{i} \\
\ldots & \ldots & \ldots \\
v_{1}^{i}+\delta_{11}^{i} & \ldots & v_{S}^{i}+\delta_{S 1}^{i} \\
\ldots & \ldots & \ldots \\
v_{1}^{i}+\delta_{1 V}^{i} & \ldots & v_{S}^{i}+\delta_{S V}^{i}
\end{array}\right]
$$

Note that the asset structure of $E$ has restricted access: although there are I insurance contracts, as many as individual types, a household of type $i$ can only purchase units of an insurance contract of type $i$, i.e. a vector of transfers $\left(v_{s}^{i}\right)$ with $\sum_{s \in S} \rho_{i s} v_{s}^{i}=0$. The market is incomplete because there are only I assets, while there are as many states as the cardinality of the set $R_{H}$, namely $A$ (and $A>I$ ). 


\subsection{Existence of a General Equilibrium with Default}

The economy in our model has incomplete asset markets. Each asset has exogenously determined and fixed yields denominated in terms of the numeraire good. The economy has restricted access, because each type of agent can only purchase one of the assets available in the economy (i.e. the insurance contract of type i).

Definition 4: With $H$ households of I types, a general equilibrium with default and recontracting consists of a price vector $p^{A *}=\left(p_{r}^{*}\right) \in$ $\mathbf{R}^{N A}$, consumption vectors $x^{i *}=\left(x_{s r}^{i *}\right)$ for each household $h$ of type $i$ with $x_{s r}^{i *} \in \mathbf{R}^{N}$ representing consumption in the aggregate collective state $r$ and individual state $s$, a vector of shortfalls $\delta_{s d}^{i}<0$, and a vector $y=\left(y_{r}^{*}\right), y_{r}^{*} \in$ $R^{N}$ representing consumption by the insurer in aggregate collective state $r$, satisfying the following : The vector $x^{i *}=\left(x_{s r}^{i *}\right)$ maximizes the utility function

$$
W^{i}\left(x^{i}\right)=\sum_{r \in R_{H}} \Pi_{r} \sum_{s=1}^{S} r_{i s} U_{s}^{i}\left(x_{s r}^{i}\right)
$$

over the set of $x^{i}=\left(x_{s r}^{i}\right)$ satisfying

$$
\begin{gathered}
p_{r}^{*}\left(x_{s r}^{i}-e_{s}^{i}\right)=v_{s}^{i}, s=1, \ldots, S \text { if } r \notin \nabla, \\
p_{r}^{*}\left(x_{s r}^{i}-e_{s}^{i}\right)=\delta_{s r}^{i}+v_{s}^{i}, s=1, \ldots, S \text { if } r \in \nabla,
\end{gathered}
$$

and

$$
\sum_{s} \rho_{i s} v_{s}^{i}=0
$$

The vector $y^{*}=\left(y_{r}^{*}\right)$ maximizes the insurer's utility function

$$
W(y)=\sum_{r \in R} \Pi_{r} U\left(y_{r}\right)
$$

over the set of $y=\left(y_{r}\right)$ satisfying

$$
p_{r}^{*}\left(y_{r}-e\right)=\sum{ }_{i, s} H_{i} r_{i s} v_{s}^{i} \text { if } r \notin \nabla
$$

and

$$
p_{r}^{*}\left(y_{r}-e\right)=c, c \leq 0 \text { if } r \in \nabla \Gamma .
$$


Finally, the market clears for each aggregate collective state $r \in R_{H}$, (13)

$$
\sum_{i} H_{i} \sum_{s=1}^{S} r_{i s}\left(y_{s r}^{* i}-e^{i}\right)+\left(y_{r}^{*}-e\right)=0 .
$$

Proposition 1 below offers the first result on the existence of a competitive equilibrium with default in a world with individual and collective risks. (All proofs are in the Appendix.) As a prepatory result we present the following

Lemma 1. Walras Law is satisfied in the economy, i.e.

$$
p_{r} \cdot \sum_{i=0} \sum_{s=1} H_{i} r_{i s}\left(y_{s r}^{i}-e_{s}^{i}\right)=0, \text { for } r=0,1, \ldots, V .
$$

The Walras's Law may not be satisfied in an economy without recontracting (see section 3.1), but it holds in the current framework with recontracting. With the help of Walras Law, we can obtain the existence of a general equilibrium as in the next proposition.

Proposition 1. Assume that the economy E satisfies A1 and A2, and that recontracting occurs after default. There exists a general equilibrium with default and recontracting in the economy $E$ with incomplete markets.

The economy $E$ is also denoted $E_{H}$ to indicate the number of its individuals. Note that the condition of individual risk implies that as the number of individuals $H$ goes to infinity, the economy $E_{H}$ converges to a limiting economy denoted $E^{\infty}$, which is identical to the limit of the Malinvaud economies $E_{M}$. Formally, $\lim _{H \rightarrow \infty} E_{H}=E^{\infty}=E_{M}$, as discussed in Section 2 and in Appendix.

Alternatively, if the number of individuals $H$ remains constant but we substitute the probability distribution $\Pi$ on $R$ by the singular probability $\Pi^{\infty}=\lim \Pi_{H}$ supported on the single aggregate collective state $r^{\infty}$, we obtain an economy $E^{*}$ with the same finite number of individuals $(H)$ but with a unique aggregate collective state $r^{\infty}$ almost surely. Then $\forall i, s \rho_{i s}=r_{i s}^{\infty}$. There is no insurance default in $E^{*}$ and excess demand is identical to expected excess demand almost surely. In per capita terms $E^{*}$ is identical to $E^{\infty}$. There is no collective risk in $E^{*}$ because there is only one aggregate collective state $r^{\infty}$ almost surely; all individual risk is covered by the insurance contracts $\left(v_{s}^{i}\right)$ which never default. $E^{*}$ behaves as $E$ is expected to, but sometimes doesn't. For this reason $E^{*}$ is called a benchmark for $E$. It is 
straightforward to show the following result:

\section{Lemma 2: The benchmark economy $E^{*}$ is a complete market economy with no default almost surely.}

\section{Complex Economies}

The introduction of a statistical asset of the ALM type transforms individual risk into collective risk of widespread default in an incomplete market economy. In our examples we showed how the complex web of contractual obligations amplifies individual default into collective default. Crucial to these examples is the complex web of contractual obligations that the economy has in equilibrium, which magnifies individual default. This section seeks to focus on the complexity of this web of transactions, and it does so by introducing a new concept that formalizes complexity. We aim to determine the extent to which there is a chain reaction of defaults in an economy where the trade patterns are highly interlinked. The economy's complexity therefore determines the extent to which there is a "multiplier" effect for policies designed to prevent financial default.

Example 3: A Complex Economy with Collective Risk of Default

The economy E in example 1 is "complex" as we are going to define: for each good there is only one type of household who is a net importer and only one type of household who is a net exporter. For each aggregate collective state $r>1 / 2$, the insurer (type 0 ) collects one unit of the numeraire good from $(1-r) H$ of type 2 households in good state and has to deliver to $r H$ of type 2 household in bad state. With limited liability, the insurer can deliver only $(1-r) / r<1$ unit of the numeraire good to those households in bad state. This is the initial default started by the insurer with an "actuarially fair" insurance contract, which is an example of the ALM asset as discussed in the previous sections.

Suppose that recontracting is not considered and the price is not yet adjusted from the equilibrium level without default: $p_{1}=p_{2}=p_{3}=1$. Without default, the original contracts specify that type 2 households deliver $4 / 5$ units of good 3 and receive 4/5 units of good 2 , type 1 households deliver $4 / 5$ units of good 2 and receive $4 / 5$ units of good 1 and type 3 households deliver $4 / 5$ units of good 1 and receive $4 / 5$ units of good 3 . The initial default by the insurer, for any $r>1 / 2$, generates a chain reaction of defaults. First, $r H$ of type 2 households have to default from the original contract as they can choose to deliver only $\frac{4}{5}\left(\frac{1-r}{r}\right)$ units of good 3 in exchange for $\frac{4}{5}\left(\frac{1-r}{r}\right)$ units of good 2. 
The total purchase order for good 2 can be computed as $\frac{4}{5}\left(\frac{1-r}{r}\right) \times r H+$ $\frac{4}{5} \times(1-r) H=\left(\frac{4}{5} H\right) \times 2(1-r)$ with $2(1-r)<1$. These purchase orders are distributed proportionally to type 1 households, with each receiving $\frac{4}{5} \times$ $2(1-r)$ units of purchase order. So all $H$ of type 1 households obtain less income and have to default on their original promise of purchasing $4 / 5$ units of good 1. Instead, each of them can purchase only $\frac{4}{5} \times 2(1-r)$ units of good 1. Similarly, type 3 households have to default and reduce their purchase of good 3.

In this economy default starts with a single agent(insurer) on an insurance contract and spreads through a complex web of transactions to $(2+r) H$ households, whenever the aggregate collective state is $r$ with $r>1 / 2, r \in$ $R_{H}$. The total amount of default for $r>1 / 2$, as compared to a benchmark economy without default, is equal to those default occurred for the promised delivering of each good,

$$
D(r)=\frac{4}{5} H(2 r-1)+\frac{4}{5} H(2 r-1)+\frac{4}{5} H(2 r-1)=\frac{12}{5} H(2 r-1) .
$$

The per capita default is equal to

$$
d(r)=\frac{D(r)}{3 H}=\frac{4}{5} \times(2 r-1)
$$

and the expected amount of default is equal to

$$
\sum_{r \in \Gamma} \Pi_{r} D(r)
$$

Our previous definition of a general equilibrium with default and recontracting allows the households to renegotiate new contracts to settle default, with the help of a set of new prices. In this example, given $r>1 / 2$, the new prices $p_{1}=p_{2}=2(1-r)$ and $p_{3}=1$ help to reach an equilibrium with recontracting as in Definition $4 . \diamond$

As already noted, there exist aggregate collective states $r$ in $R$ where the insurer cannot meet promised payments to individuals, namely when $r \in \Gamma$. In the (finite) perfect foresight economy $E$, individuals take these defaults into account, and adjust their consumption in state $r$ appropriately (Section 3, definition 4). In Section 3 we also defined a benchmark economy for the purpose of comparing it with $E$, and measuring default and complexity. We consider default in a state $r \in \Gamma$ where the insurer fails to honor its payment $v_{s}^{i}$ to an individual $h$ of type $i$ in individual state $s$ at a collective state $r$, and examine how many other individuals default as a consequence. 
Default therefore identifies the decrease in the value of a contract resulting from a failure in payments by the insurer. The complexity of the economy measures how many other individuals default in state $r$ as a consequence of the default by the insurer on payments to individual of type $i$. (see Example 1)

Definition 5 : The economy $E$ is said to have complexity $k$ at a default state $r$, when there are $k$ defaults following any one default, at any equilibrium allocation of $\mathrm{E}$.

Note that the concept of default considered here refers to contracts (net trades) for delivery to the "market exchange" or to an "auctioneer", as in the Arrow - Debreu market formulation. In other words, no information is given here about who trades with whom or how much. Such information is explicitly forbidden by the assumption of preserving privacy. In our context, default involves simply an equilibrium net trade vector at a default state which differs from that contracted at a no - default equilibrium.

The concept of complexity and the analysis of complex economies is useful for two reasons. The first is for gauging the collective nature of the states of default in the economy $E$ defined in Section 3. For example, in an economy with complexity $k \geq H / 2$, a default state involves defaults by a large number of individuals. The default states in $E$ are always collective states, because they depend on the number of people in a bad state across the population. However, the collective nature of these states is emphasized further when the complexity of the economy if high. In such economies the states of default not only depend on a collective state (the number of people in a given individual state) but also affect a large number of individuals as well. This is formalized in Proposition 2.

Consider now an economy $E$ with $N$ goods, $H$ individuals of I different types. There are $S$ individual states. Each individual of type $i$ has an endowment $e_{s}^{i}$ and utility functions as in (2) and $W$ (Section 3, (10)). In addition, an $S$ vector of transfers $\left(v_{s}^{i}\right)$ is available to each individual of type $i$ provided it has zero expected value. The economy can be described therefore as $E=\left(N, H, \mathrm{I}, e_{s}^{t}, W^{i}, W\right)$. Insurance contracts do not appear in this parameterization, since they are chosen as an optimal set of transfers $\left(v_{s}^{i}\right)$, $s=1, \ldots, S$, by the individuals of type $i$, among all possible transfers of zero expected value. The space $E$ of all such economies can be parameterized by the endowments $\left\{e_{s}^{i}\right\} \in R^{N S I}$ and by the utilities $W^{i}, i=1, \ldots, I$, and $W$, and topologized by the product topology $\tau$ defined by the Euclidean metric on endowments and the Whitney $C^{2}$ topology on the space of $C^{2}$ utility functions. The Whitney topology on the space of $C^{2}$ functions $U^{h}: R^{N} \rightarrow R$ is defined by specifying neighborhoods of zero, since this is a linear space (Smale (1974), Peixoto (1967)). Such a neighborhood $M_{f}$ is defined by each strictly positive continuous function $f: R^{N} \rightarrow R$ as follows: 
the function $U \in V_{f}$ iff $\|U(x)\|<f(x),\|D U(x)\|<f(x), \| D(U(x) \|<f(x)$ for all $x \in R^{N}$ where $D U$ and $D^{2} U$ are the first and second derivatives of $U$, and $\|$.$\| is the Euclidean norm in finite dimensional spaces. An open$ set of economies in the space $\mathbf{E}$ means an open set in the topology $\tau$, as endowments and utilities vary.

Proposition 2. Let $N>H$ and $k \geq 2$. There exists in $\mathbf{E}$ an open set of economies of complexity $k$.

Proof : In the Appendix.

Proposition 2 shows that there exists an open set of economies $E$ with complexity $k$, for any $k \geq 2$. This establishes that in an open set of economies the states of default affect at least $k$ individuals. Therefore when $k$ is large, the risk of default cannot be hedged properly by insurance.

The following corollary refers to small variations of the endowments of the economy, leaving utilities invariant. The set of economies is now parameterized by its endowments and these are endowed with any bounded measure which is positive on open sets. The corollary follows from Propositions 1 and 2 and the fact that open sets have positive measure.

Corollary 1: Let $N \geq H$, and $k \leq H$. Then there exists a set of positive measure of Arrow -Debreu economies which are $k$ complex, for any default level $\delta>0$.

\section{$5 \quad$ Asymptotic Risk and Financial Reserves}

In this section we consider the asymptotic properties of our economy with default. We also examine whether the default problem goes away once we incorporate "reserves" into the equation to reduce such risks. This section considers this possibility and shows that, while the risk of default can be reduced using reserves, it cannot be eliminated.

Consider now the economy $E$ defined in Section 3, which we now shall denote also $E_{H}$ in order to highlight the number of its individuals, $H$. In order to study the asymptotic properties of this economy, we shall analyze a sequence of economies $E_{H}$ as the number of individuals tends to infinity, i.e. $H \rightarrow \infty$.

In order to study the asymptotic behavior of economies where assets are valued in terms of statistics, (i.e. ALM assets) we now need a few definitions. Recall that the set $\nabla_{H}$ represents all states of default in the economy $E_{H}$, and $\Pi_{H}\left(\nabla_{H}\right)$ its measure, and that convergence of probabilities means weak convergence (Billingsley, 1968). Consider an economic statistic on an endogenous risk, such for example the expected value of total default of the 
economy $E_{H}$, or the expected value of per - capital default of $E_{H}$. Formally, an endogenous economic statistic is defined as a continuous function from the space $\left(F_{H} \times \mathbb{E}_{H}\right)$ of all probability distributions on the space of collective states $R_{H}$ times the space of economies $\mathbb{E}_{H}$, into the real numbers, $\mathbf{R}$, i.e. $s\left(g, E_{H}\right) \in \mathbf{R}$. Notice that an endogenous economic statistic is defined continuously for probability distributions and economies with a population of a fixed size $H$.

Now consider as in Section 3 the product of the $(S-1)$ - dimensional unit simplex with itself I times, denoted $\Delta^{I}$. A point in $\Delta^{I}$ represents a proportion of each type $i=1, \ldots, I$ in each of the $S$ individual states. Then a probability measure $\Pi_{H}$ on $R_{H}$ defines a measure on $\Delta^{I}$, supported on a finite subset of $\Delta^{I}$, given say by a density function $\Pi_{H}(r)$ for $r \in R_{H}$, as represented in Figure 2 below (see also Malinvaud (1973)):

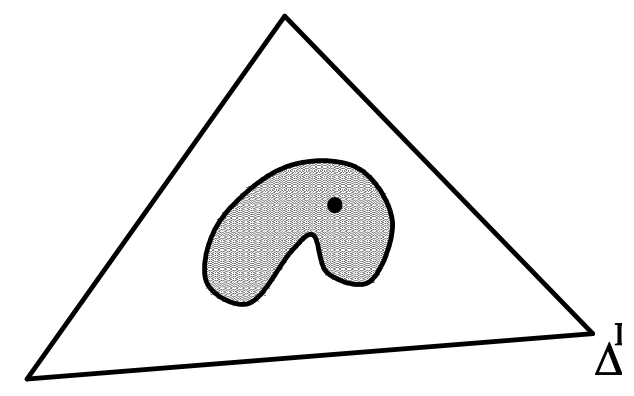

The shaded area contains the support of the distribution over collective states in the finite economy; the point inside it indicates the support of the limiting distribution which is a point because of the assumption of individual risk.

As already mentioned, the assumption of individual risk in Section 3, implies $\lim _{H \rightarrow \infty}\left(\Pi_{H}\right)=\Pi^{\infty}$, a degenerate measure on $\Delta^{I}$ supported in one point only, denoted $r^{\infty}$. Note that even if the endogenous economic statistic $s\left(g, E_{H}\right)$ is a continuous function of $g \in F_{H}$ for a fixed population size $H$, convergence in measure of the probabilities $\Pi_{H}$ need not imply that $\lim _{H \rightarrow \infty} s\left(\Pi_{H}, E_{H}\right)=s\left(\Pi^{\infty}, E^{\infty}\right)$, since the value of the endogenous statistic $s$ depends on the behavior of the economy $E_{H}$ as well as on the probabilities $\Pi_{H}$.

In the following, if $\left\{b_{n}\right\}$ is a sequence of real numbers we say that $\left\{b_{n}\right\}=$ $O(\ln H)$ if $\lim _{H \rightarrow \infty}\left[b_{n} / \ln H\right]=\infty$. A class of economies is called robust when it is an open set in the topology on the space of all economies defined in Section 4. If the class of economies has variable population $H=1,2, \ldots$, 
then we say that the class is robust when it is an open set under the topology defined in Section 4 for each population size $H$.

The following Proposition 3 considers a class of economies of population size $H$ and of complexity $H$. Figure 3 below illustrates such an economy. It consists of a number of traders each of whom owns one good only, and derives utility from a different good. The economy has one importer and one exporter for each good. In this economy, default by one trader leads to default by all traders, as shown in detail in the Appendix. Therefore this economy has maximum complexity. As $H$ increases, the number of agents and of goods increases with $H$ :

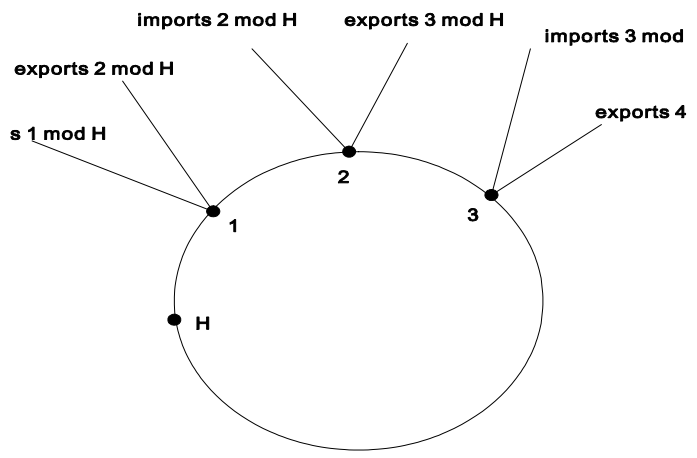

Proposition 3: Consider a sequence of increasingly large and complex economies $E_{H}$ with a population of $H$ individuals facing individual risk, $H \rightarrow \infty$ and satisfying $\Pi_{H}\left(\nabla_{H}\right)=O(\ln H)$. Then the expected value of default increases with the size of the population H. The result is robust as it holds for an open set of economies.

The following example shows a class of economies $E_{H}$ in which as the number of agents increases and the number of goods remains constant or increases, the per capita endowment of each agent need not increase, and default occurs to every household in the economy.

Example 4: There exists a robust class of economies in which autarky occurs in states of default, for all population levels.

Consider an economy $E_{H}$ with $H_{i}$ households of type $i, i=1, \ldots, I$, a total population of $\sum_{i} H_{i}=H$. There are $N \geq 1$ goods. One type, type 1 , faces uncertainty: the households of type $i$ can be in one of two individual states $S=\{0,1\}$. The unfavorable state is 1 , and 0 is the favorable state. 
The endowments of households of type 1 are $(0, \ldots, 0) \in R^{N}$ in the unfavorable state and $(1,0, \ldots, 0)$ in the favorable state where the first good is the numeraire. Assume that the distribution of risks over aggregate collective states for households of type 1 is given by a probability distribution $\Pi_{H}$ defined by $\Pi_{H}(1, \ldots, 1)=1 /(2 \ln H) ; \Pi_{H}(1, \ldots, 1,0, \ldots, 0)=\Pi_{H}\left\{1 / 2 H_{i}\right.$ in state 1 and $1 / 2 H_{i}$ in state 0$\}=1 /(2 \ln H)$; and $\Pi_{H}(0, \ldots, 0)=1-(1 / \ln H)$. For all other aggregate collective states $r, \Pi_{H}(r)=0$. The individual probabilities for households of type 1 are $\rho_{o}=1 /(4 \ln H)+(1-1 / \ln H)=$ $(4 \ln H-3) /(4 \ln H)$, and $\rho_{1}=1 /(2 \ln H)+1 /(4 \ln H)=3 /(4 \ln H)$, so that $\rho_{o}+\rho_{1}=1$. Then the probabilities $\Pi_{H} \rightarrow \Pi^{\infty}$ weakly, where $\Pi^{\infty}$ is the probability measure which assigns measure 1 to the aggregate collective state $r^{\infty}$ where everyone of type $i$ is in the favorable state $s=0$, i.e. $r_{i s}^{\infty}=1$ if $s=0, r_{i s}^{\infty}=0$ if $s=1(i=1)$. Therefore the conditions for individual risk are satisfied.

Individuals of type 1 purchase actuarially fair insurance to equate consumption in the two states: they contract to pay a premium $\rho_{1}$ in state 0 and receive a payment $\rho_{0}$ in state 1 . For any finite $H$, there is one aggregate collective state of insurance default, denoted $r_{H}$, which occurs with probability $1 /(2 \ln H)$ : when all households of type 1 are in state 1 . The probability of $r_{H}$ goes to 0 with $\mathrm{H}$. Assume now that the economy $E_{H}$ is complex, as in the example of Section 3 and as illustrated in Figure 3; it has a unique equilibrium in which there is one type which is a net importer of each good, and one type which is a net exporter of each good. At the equilibrium prices of $E_{H}$ all the households of type 1 have zero endowments and trade nothing in the default state; by construction, no one else will trade in this state either, leading to autarky. Therefore as $H$ increases, the economy is always in autarky in the default state $r_{H}$. This example is robust for small changes in initial endowments and preferences, since the net trades at equilibrium are a continuous function of endowments and preferences in the chosen topology. $\diamond$

We may assume that the excess (positive) returns on insurance premium over payments are saved as "reserves", and used to cover the (negative) shortfalls in the unfavorable collective states. A natural question is whether default may be avoided by requiring that the agents hold their positive profits from favorable collective states in financial reserves and use these reserves to satisfy claims in unfavorable collective states. However, unless reserves which equal the maximum exposure are required, the problem of default emerges all the same and leads to the same consequences. The only difference is in the probability of default which is typically decreased. This provides support to policies requiring some forms of reserves in the insurance and banking industry and in financial markets, which can enhance the financial stability of the economy. We show that requiring reserves reduces the problem of 
default.

Proposition 4: Increasing financial reserve will reduce the probability of default in any economy, but a positive probability of default still remains.

\section{Conclusion}

We have analyzed the effect of introducing ALM assets in a large but finite economy. Examples of ALM assets are actuarially fair insurance contracts, or shares in a firm which maximizes expected profits. States of default emerge because ALM assets promise deliveries that sometimes exceed physical endowments.

Proposition 1 proved the existence of an equilibrium with recontracting and endogenous uncertainty on the contract's default. The new states of default in $E$ are collective states because they depend on collective events, such as the proportion of the population in each individual state. We showed that in complex economies many individuals default at once at each state of default, emphasizing the collective nature of default.

Proposition 2 shows that there is an open set of complex economies of complexity $k$, for any $k \geq 2$. In such economies default by one individual leads to default by $k$ individuals, due to the pattern of trading.

The introduction of ALM assets to hedge against individual risk therefore may increase collective risk of default.

We studied expected default as the population size increases without bounds. At the limit, and only at the limit, the economies have no default. This is because the distribution of risks across the population converges with certainty to a known one.

Although the introduction of new assets, such as health insurance policies, may enhance the welfare of individuals, our results illustrate a familiar concern about financial innovation. The concern is that the introduction of new financial assets could in some circumstances lead to more instability, namely to new states of collective default. The results we presented formalize this concern. They offer a way to measure the benefits of financial innovation, as well as its drawbacks.

The key is to understand the two circumstances under which collective risk increases with introduction of new financial assets. These circumstances are: the assets are ALM, and the economies are complex. The first feature of the problem, that the assets be ALM, is almost inevitable in large economies with individual risk, because of the difficulty of creating assets that depend on long list of individual characteristics, most of which are difficult to ob- 
serve. So this first condition cannot be avoided. The second feature refers to the complexity of the economy. The introduction of an asset typically increases the web of trading in an economy and thus its complexity. Certain assets increase the collective risk of default more than others. They create "correlated" risks which cannot be properly insured. The computation of the collective risk of default and the total expected default from different assets, as defined in Section 5, could help to determine the extent of collective risk introduced by the asset.

An interesting area of research would include the computation of the costs and benefits from the introduction of new securities. The benefits can be measured in terms of Pareto improvements in welfare, and the costs could be measured in terms of the increase is collective risks and complexity of the economy, which make it more vulnerable to financial instability.

The other implication of our results is that they help to formalize a "multiplier effect" for policy. In a complex economy, financial policies which succeed in preventing default by one agent also prevent, by a chain reaction, a large number of other defaults at no additional cost. Therefore the benefits have a "multiplier effect". Our results provide support for the policy of requiring reserves to enhance financial stability.

The complexity of the economy is not a problem in itself, unless it leads to large correlated risks. If following the introduction of an ALM asset a second layer of securities is introduced to deal with the endogenous risk created by the first, and the latter securities are also of the ALM type, then the process is replicated. More endogenous uncertainty may be created, piling up the risk of default of an asset which was introduced to hedge against the risk of default of another. These results also suggest that large and complex market economies with individual and collective risks are likely to be incomplete. 


\section{References}

Arrow, K.J. (1953) "The Role of Securities in the Optimal Allocation of Risk - Bearing", Econometrie, Proceeding of the Colloque sur les Fondements et Applications de la Theorie du Risqe en Econometrie, Centre National de la Recherche Scientifique, Paris, France. English translation: Review of Economic Studies (1964) 31: 91 - 96.

Arrow, K.J. (1963) "Uncertainty and the Welfare Economics of Medical Care," American Economic Review , 53: 941 - 73.

Arrow, K.J. and R.C. Lind (1970) "Uncertainty and the Evaluation of Public Investments," American Economic Review, 364 - 378.

Billingsley, P.(1968) Convergence of Probability Measures, John Wiley.

Cass, D., G. Chichilnisky and H.-M. Wu (1996) "Individual Risk and Mutual Insurance," Econometrica, 64: 333-341.

Chichilnisky, G. and G. M. Heal (1993) "Global Environmental Risks" Journal of Economic Perspectives, Vol. 7, No. 4, Fall 1993, 63-86.

Chichilnisky, G. and P. Gruenwald (1995) "Existence of Optimal Growth Paths with Endogenous Technology" Economic Letters Vol. 48, 433-439.

Chichilnisky, G.(1996) "Markets with Endogenous Uncertainty: Theory and Policy," Theory and Decision, 41: 99-131.

Chichilnisky, G.(1999) "Existence and Optimality of a General Equilibrium with Endogenous Uncertainty," in G. Chichilnisky ed. Markets, Information and Uncertainty, Cambridge University Press.

Chichilnisky, G., J. Dutta and G. M. Heal (1991) "Price Uncertainty and Derivative Securities in a General Equilibrium Model," Working Paper, Columbia University.

Chichilnisky, G.C. and H.-M. Wu (1992), "Financial Innovation and Endogeneous Uncertainty in Incomplete Asset Markets," Technical Report No. 50, Stanford Institute for Theotherical Economics (SITE), Stanford University, August 1992.

Debreu, G. (1959) The Theory of Value, Wiley.

Debreu, G. (1982) "Existence of a Competitive Equilibrium" Chapter 15, Handbook of Mathematical Economics, Vol. II, ed. by K. Arrow and M. Intriligator, North Holland.

Diamond, D. W. and P. H. Dybvig (1983) "Bank Runs, Deposit Insurance, and Liquidity," Journal of Political Economy, 91: 401 - 19.

Dubey, P., J. Geanakoplos, and M. Shubik (2005) "Default and Punishment in General Equilibrium," Econometrica, 73: 1-37.

Dubey, P. and J. Geanakoplos (1989) "Liquidity and Bankruptcy with Incomplete Markets: the Exchange Case," Cowles Foundation Paper No. 900. 
Duffie, D. (1992) "The Nature of Incomplete Security Markets," in J. Laffont ed. Advances in Economic Theory, Cambridge University Press.

Geanakoplos, J. and H. Polemarchakis (1986) "Existence and Regularity of Constrained Suboptimality of Competitive Allocations when Markets are Incomplete," in Equilibrium Analysis : Essays in Honor of Kenneth Arrow, ed. by W. Heller, R. Starr and D. Starrett, Cambridge University Press, Vol. III.

Hahn, F. (1999) "A Remark on Incomplete Market Equilibrium," in G. Chichilnisky ed. Markets, Information and Uncertainty, Cambridge University Press.

Hildenbrand, W. (1971) "Random Preferences and Equilibrium Analysis," Journal of Economic Theory, 3: 414 - 429.

Huang, P. and H.-M Wu (1999) "Market Equilibrium with Endogenous Price Uncertainty and Option" in G. Chichilnisky ed. Markets, Information and Uncertainty, Cambridge University Press.

Kurz, M. (1974) "The Kesten - Stigum Model and the Treatment of Uncertainty in Equilibrium Theory," in M. S. Balch, D. L. McFadden, and S.Y. Wu ed., Essays on Economic Behavior under Uncertainty, North - Holland.

Kurz, M. (1994) "On the Structure and Diversity of Rational Beliefs," Economic Theory, 4: 877-900.

Kurz, M. and H.-M. Wu (1996) "Endogenous Uncertainty in a General Equilibrium Model with Price-Contingent Contracts," Economic Theory, 8: 461-488.

Malinvaud, E. (1972) "The allocation of individual risk in large markets," Journal of Economic Theory, 4: 312 - 328.

Malinvaud, E. (1973) "Markets for an exchange economy with individual risk," Econometrica, 41: 383- 409.

Peixoto, M. (1967) "On an Approximation theorem of Kupka and Smale," Journal of Differential Equations, 3: 214 - 227.

Smale, S. (1974) "Global Analysis and Economics Ila: Generalization of a theorem of Debreu," Journal of Mathematical Economics, 1: 1 - 14.

Svensson, L. E. O. (1981) "Efficiency and speculation in a model with price contingent contracts," Econometrica, 49: 131 - 151.

Wu, H.-M. (1988) "Unemployment Equilibrium in a Random Economy," Journal of Mathematical Economics, 17: 385 - 400.

Wu, H.-M. and W.C. Guo (2003) "Speculative Trading with Rational Beliefs and Endogenous Uncertainty" Economic Theory, 21: 263-292.

Wu, H.-M. and W.C. Guo (2004) "Asset Price Volatility and Trading Volume with Rational Beliefs," Economic Theory, 23: 795-829.

Zame, W. (1993) "Efficiency and the Role of Default when Security Markets are Incomplete," American Economic Review, 83: 1142-1164. 


\section{Appendix}

\section{A.1 Extending Malinvaud's Model of Individual Risks}

In this paper we extend Malinvaud's model to include several types of agents, identified by their endowments, utilities, and propabilities. One example of Malinvaud's model is provided by identically distributed and independent (iid) random variables. With iid's there is no connection between the individuals' risks; furthermore, the probability of a collective state (e.g. how many people are ill) is derived, indeed defined from, the probability of each individual's risks. Instead, Arrow - Debreu's approach to uncertainty described by "states of nature" is an extreme case of collective risk. In Arrow Debreu models all risk is collective, and the probability distribution of risks for one individual is derived from, indeed is identical to the distribution for collective risks, because all individuals are exposed to the same risks simultaneously. However, between these two extreme cases there are many shades of risks which combine in different ways features of individual and collective risks. They are represented by random variables which have individual and collective components simultaneously.

Individual risk has a specific meaning as defined in Section 2. Malinvaud (1973, p. 387) establishes that the probability that an aggregate collective state $r$ obtains and that simultaneously, for a given household $h$ of type $i$, a particular state $s$ also obtains is $\Pi(r) r_{i s}$. The probability $\rho_{i s}$ that, for a given $h$ of type $i$, a particular individual state $s$ obtains is therefore given by

$$
\rho_{i s}=\sum_{r \in R_{H}} \Pi(r) r_{i s}
$$

\section{A.1.1 The Arrow-Debreu Model with Contingent Contracts}

Consider the set $\Omega$ of all collective states $\sigma$ consisting of a realization of one of the $S$ states for each of the $H$ households in the economy; $\Omega$ has $S^{H}$ elements. The endowments $e_{h}$ of a household $h$ is an $N S^{H}$ dimensional vector. For each household $h$ of type $i$ the endowment is the same across all collective states in $\Omega$ in which $h$ is at the same individual state $s$. A price vector $p$ is an $N S^{H}$ dimensional vector. An Arrow - Debreu equilibrium is a price vector $p^{*}$ and $H$ consumption plans $x_{h}^{*}$ with $N S^{H}$ components each, such that if individual $h$ is of type $i, x_{h}^{*}$ maximizes $W^{i}\left(x_{h}\right)$ of (1) subject to

$$
p\left(x_{h}-e_{h}\right)=0
$$

and markets clear: 
(A.2)

$$
\sum_{h=1}^{H}\left(x_{h}^{*}-e_{h}\right)=0 .
$$

\section{A.1.2 Extending Malinvaud's Model to economies with Arrow- Lind-Malinvaud Assets}

Malinvaud notes that the number of contingent markets in the Arrow - Debreu model is impossibly high, indeed equal to $N S^{H}$ (an exponential function of the number of individuals). He furthermore notes that as the population increases, then in the limit all contracts contingent on collective states become irrelevant. This is because with probability one, all collective states become equal, with probability one, to the single aggregate collective state $r^{\infty}$ having a fixed proportion $r_{i s}^{\infty}$ of people of each type $i$ in each individual state $s$. Since the total initial endowments in the economy and total number of people with a given preference are fixed, this leads to a fixed set of prices for the $N$ commodities, $p \in R^{N}$ (Malinvaud (1973), Proposition 5). For this reason, he suggests that, as the number of individuals goes to infinity: "The economy should be able to work properly with just $N$ markets, one for each good" (Malinvaud (1973), P.401). This requires, however, that individuals should be able to hedge appropriately their risk between bad and good individual states. For this purpose, Malinvaud introduces individual insurance: contingent commodities are substituted by an insurance system operating as a redistribution scheme. Suppose that the individual of type $i$ holds insurance contracts that will give him or her the net transfer $v_{s}^{i}$ of the numeraire good if he or she is in state $s$. Let now $x_{s}^{i} \in R^{N}$ be the consumption vector by individual $h$ of type $i$ of the $N$ goods in state $s$. Then if $p \in R^{N}$ is the vector of commodity prices, the individual of type $i$ has a budget constraint:

$$
p\left(x_{s}^{i}-e_{s}^{i}\right)=v_{s}^{i},(s=1, \ldots, S)
$$

Risk coverage means that $v_{s}^{i}$ will be positive in unfavorable states and correspondingly negative in favorable states. The individual chooses net transfers $v_{s}^{i}$, depending on the terms on which such insurance contracts are offered. Malinvaud assumes that a transfer vector $v_{s}^{i}$ is accessible to individual $h$ of type $i$ if and only if it is actuarially fair, i.e. its expected value is zero:

$$
\sum_{s=1}^{S} \rho_{i s} v_{s}^{i}=0
$$


This is admittedly a strong assumption, but we note that nothing in what follows changes if instead the expected value is equal to a constant $c_{i}>0$, where $c_{i}$ could be the return on investment across the economy in equilibrium, or a regulated level of profits. This assumption could be formalized as an equilibrium condition on the supply of insurance. Arrow and Lind (1970) proposed that the expected profit should be the preferred maximum for public firms in economies with individual risks, and indeed share holding in such firms would also be assets valued as a function of their expected value. With these applications in mind, we consider more generally any asset which is offered at a price which is a function of its expected value, and we call this an Arrow - Lind - Malinvaud (ALM asset). The introduction of such an asset has the effect of modifying the right hand side of equation (A.4) leading to

(A.5)

$$
\sum_{s=1}^{S} \rho_{i s} v_{i s}=c_{i}
$$

Extending Malinvaud's equilibrium $E_{M}$ with insurance to economies with several types of agents is defined as a vector of prices $p^{*} \in R^{N}$, and for each household of type $i=1, \ldots, I$, a consumption plan $x^{i *}=\left(x_{s}^{i *}\right)_{s=1}^{S} \in$ $R^{N S}$ which maximize $W^{i}$, as defined in (3), subject to (A.3) with the net trasfer $v_{s}^{i}$ satisfying (A.4), or equivalently

$$
\sum_{s=1}^{S} \rho_{i s} p^{*}\left(x_{i s}^{*}-e_{i s}\right)=0
$$

and the expected total excess demand $\xi(p)$ is zero :

(A.7)

$$
\xi\left(p^{*}\right)=\sum_{i} H_{i} \xi^{i}\left(p^{*}\right)=\sum_{i} H_{i} \sum_{s=1}^{S} \rho_{i s}\left(x_{s}^{i *}-e_{s}^{i}\right)=0 .
$$

When the right hand side of equation (A.6) is substituted by $c_{i}$ as in (A.5), then we call this an equilibrium with individual risk and Arrow - Lind - Malinvaud (ALM) assets. Related concepts of equilibrium with zero expected excess demand have been studied by Hildenbrand (1971) and $\mathrm{Wu}(1988)$. 


\section{A.1.3 An extension to Markets with an Infinite Number of Indi- viduals of Each Type}

Assume now that there are infinitely many individuals of each type $i$. Then by the assumption of individual risk, $\rho_{i s}=r_{i s}^{\infty}$, where $r^{\infty} \in \Delta^{I}$ is the support of the limiting probability $\Pi^{\infty}$ namely the (unique) limiting aggregate collective state giving a fixed proportion $r_{i s}^{\infty}$ is of individuals of type $i$ which are in individual state $s$. Per capita expected excess demand $(1 / H) \xi(p)$ is now used instead of expected excess demand because the latter may not be a finite number in the limit, as $H \rightarrow \infty$. The equilibrium condition is now therefore written as

$$
(1 / H) \xi(p)=0
$$

almost surely as $H \rightarrow \infty$.

In the limit there is no default, since the proportion of people in an individual state $s$ within an aggregated collective state $r$ is exactly $r_{i s}^{\infty}=\rho_{i s}$ by the assumption of individual risk. This limiting economy is denoted $E_{M}^{\infty}$. It is straightforward to show Pareto optimality of the allocations in $E_{M}^{\infty}$.

\section{A.1.4 The Utility Function of Households}

Here we summarize how to represent the utility functions in different forms, as in Section 3 of the paper. The von - Neuman and Morgenstern utility function can be written as:

$$
W^{i}\left(x_{h}^{i}\right)=\sum_{\sigma} \Pi_{\sigma} U_{s(h, \sigma)}^{i}\left(x_{h \sigma}^{i}\right)
$$

where $x_{h \sigma}^{i} \in R^{N+}$, indicating that the $h$ household of type $i$ has preferences on consumption which may be represented by a "state separated" utility function $W^{i}$ defined from $S$ elementary utility functions $U_{s}^{i}$. The functions $U_{s}^{i}$ are assumed to be $C^{2}$, strictly increasing, strictly quasi concave, and the closure of the indifference surfaces $\left\{\left(U_{s}^{i}\right)^{-1}(x)\right\} \subset \operatorname{int}\left(R^{N+}\right)$ for all $x \in R^{N+}$. We consider, like Malinvaud (1973), an important class of cases in which the activity of the household $h$ depends on $\sigma$ only through the aggregate collective state $r(\sigma)$. If household $h$ takes into account first what happens to her or him i.e. $s=s(h, \sigma)$, and second which frequency distribution $r(\sigma)$ happens

to appear, but nothing else, then the consumption plan $x_{s \sigma}^{i}=x_{s(h, \sigma)}^{i}(r(\sigma))$. The summation with respect to collective states $\sigma$ can now be made first with respect to each aggregate collective state. To a particular $r$ and $s$ for which $r_{s} \neq 0$, there usually corresponds a number of $\sigma$ leading to $r(\sigma)=r$ 
and $s(h, \sigma)=s$, hence to the same $U_{s(h \sigma)}^{i}\left(x_{h \sigma}^{i}\right)=U_{s}^{i}\left(x_{s}^{i}(r)\right)$. Hence $W^{i}$ may also be written as

(2)

$$
W^{i}\left(x^{i}\right)=\sum_{r \in R_{H}} \Pi(r) \sum_{s=1}^{S} r_{i s} U_{s}^{i}\left(x_{s}^{i}(r)\right),
$$

which depends on the type $i$ but not on the household $h$. But if we make the further assumption that the household $h$ only takes into account what happens to him/her, then the utility function of the $i-t h$ type of household in (1) can be rewritten as

$$
W^{i}\left(x^{i}\right)=\sum_{s=1}^{S} r_{i s} U_{s}^{i}\left(x_{s}^{i}\right)
$$

where $x_{s}^{i} \in R^{N+}$ is the consumption of a household of type $i$ in individual state $s$ (Malinvaud (1973), $p$ 390, (12)). Clearly $x_{h \sigma}=x_{s}^{i}$ if individual $h$ is of type $i$, and is in individual state $s$ at the collective state $\sigma$.

\section{A.2 Proof of Results}

\section{Proof of Proposition 1:}

The first part of the proof of Proposition 1 consists of verifying that Walras Law is satisfied in the model of Theorem 1; it suffices to prove this for the case where the penalty for the insurer $c=0$; the same proof follows for any given $c \leq 0$. We will first prove Lemma 1 .

Let $\Delta_{r}=\left\{p_{r} \in R^{N}: \sum_{n=1}^{N} p_{r n}=1\right\}$ be the price simplex for the aggregate collective state $r=0, \ldots, V$. After we find the equilibrium price $p_{r}^{*} \in \Delta_{r}$ with $p_{r n}^{*}>0$, we can renormalize to make $p_{N}^{*}=1$ for the numeraire good. Let the price simplex be denoted $\Delta=\Delta_{o} \mathrm{x} \ldots \mathrm{x} \Delta_{V}=X_{r=0}^{V} \Delta_{r}$. In the aggregate collective state $r$, the total insurance payments to all individual agents of type $i=1, \ldots, I$ is

$$
T_{r}=\sum_{i=1} \sum_{s=1} H_{i} r_{i s} v_{s}^{i}, r=0,1, \ldots, V .
$$

where $r_{i s}$ is the proportion of type $i$ agents in state $s$ given the aggregate collective state $r$. If $r_{i s}=\rho_{i s}$ for $i=1, \ldots, I$ and $s=1, \ldots, S$, then we know that $T_{r}=0$ from $\sum_{s=1}^{S} \rho_{i s} v_{s}^{i}=0$ (actuarially fair insurance). Otherwise $T_{r} \neq 0$. If $T_{r} \leq 0$ there is no default and the insurer $(i=0)$ has net income $-T_{0}$ to be spent on consumption goods in state $r=0$. If $T_{r}>0$, the insurer has to default and consume nothing (the insurer has zero endowment, $e^{o}=0$ ) 
with the provision of limited liability which corresponds to the default state $r=1, \ldots, V$. The shortfalls $\delta_{s r}^{i}$ are chosen then to satisfy the provision of limited liability:

(A.10)

$$
\sum_{i=1} \sum_{s=1} H_{i} r_{i s}\left(v_{s}^{i}+\delta_{s r}^{i}\right)=0 \text { for } r=1, \ldots, V
$$

$$
\text { If } v_{s}^{i} \leq 0 \text {, then } \delta_{s r}^{i}=0 \text {. }
$$

$$
\text { If } v_{s}^{i}>0, \text { then } \delta_{s r}^{i} \leq 0 \text { and } v_{s}^{i}+\delta_{s r}^{i} \geq 0 .
$$

Equation (A.11) means that there is no shortfall when the insurer does not pay in state $s$. Equation (A.12) means that shortfalls happen only when the insurer is supposed to pay according to the actuarially fair insurance contract, and the shortfalls cannot exceed the originally promised payment. Now we can state and prove the Walras' Law in our economy.

For $r=0$, and $i=1, \ldots, I, p_{r}\left(y_{s r}^{i}-e_{s}^{i}\right)=v_{s}^{i}$, from the budget constraint and $\delta_{s r}^{i}=0$. For $r=0$ and $i=0$ (insurer), $p_{r}\left(y_{r}^{o}-e^{o}\right)=p_{r} y_{r}=-T_{o}$. Hence $p_{r} \sum_{i=0}^{I} \sum_{s=l}^{S} H_{i} r_{i s}\left(y_{s r}^{i}-e_{s}^{i}\right)=\sum_{i=1}^{I} \sum_{s=1}^{S} H_{i} r_{i s} v_{s}^{i}-T_{o}=0$ from (19) and $H_{o}=1, r_{o s}=1$. For $r=1, \ldots, V, p_{r} \cdot\left(y_{s r}^{i}-e_{s}^{i}\right)=v_{s}^{i}+\delta_{s r}^{i}$ from the budget constraint. Summing over $i$ and $s$ we have

$$
p_{r} \cdot \sum_{i=0}^{I} \sum_{s=1}^{S} H_{i} r_{i s}\left(y_{s r}^{i}-e_{s}^{i}\right)=\sum_{i=1}^{I} \sum_{s=1}^{S} H_{i} r_{i s}\left(v_{s}^{i}+\delta_{s r}^{i}\right)=0
$$

from (A.10), for $r=1, \ldots, V$. Hence Lemma 1 is proved. $\diamond$

Since $W^{i}\left(y^{i}\right)$ is additively separable across $r$ and $s$, an equilibrium can be represented as a pair $(p, y)$ with $p=\left(p_{r}\right), r=0, \ldots, V, p_{r} \in \Delta_{r}$, and $y \in R^{I N S(V+1)}$, such that:

(A.13) $y=\left(y_{s r}^{i}\right), y_{s r}^{i}$ is in the demand correspondence $D_{s r}^{i}\left(p_{r}\right)=\left\{y_{s r}^{i} \in\right.$ $R^{N}: y_{s r}^{i}$ maximizes $U^{i}\left(y_{s r}^{i}\right)$ within $\left.B_{s r}^{i}\left(p_{r}\right)\right\}$, where

(A.14) $B_{s r}^{i}(p)$ is the budget set $\left\{y_{s r}^{i} \in R^{N}: p_{r}\left(y_{s r}^{i}-e_{s}^{i}\right)=v_{s}^{i}+\delta_{s r}^{i}\right\}$ for $s=1, \ldots, S, r=0, \ldots V$, and markets clear:

(A.15) $0 \in \Phi_{r}\left(p_{r}\right)$ the excess demand correspondence $\sum_{i=0}^{I} \sum_{i=1}^{S} H_{i} r_{i s}\left(D_{s r}^{i}\left(p_{r}\right)-\right.$ $\left.\left\{e_{s}^{i}\right\}\right)$ for $r=0, \ldots, V$.

For each $r$ the budget set $B_{s r}^{i}\left(p_{r}\right)$ defines a non empty, compact, convex valued and continuous correspondence, so that $\Phi_{r}\left(p_{r}\right)$ is a non empty, convex - valued and upper hemi-continuous correspondence (Berge's theorem). Furthermore, the excess demand correspondence $\Phi_{r}$ satisfies Walras' Law for 
each $r$ (Lemma 1), and the boundary condition of Debreu (1982, p. 722). Therefore all the conditions of Theorem 8 of Debreu $(1982, p .722)$ are satisfied so that there exists a $p_{r}^{*}$ such that $0 \in \Phi_{r}\left(p_{r}^{*}\right)$. The vector $p^{*}=\left(p_{r}^{*}\right)$ and the corresponding allocation $y^{*}(p)$ is an equilibrium, completing the proof. $\diamond$

Proof of Proposition 2: This proof has two steps: in the first step we construct an example of a complex economy, E. In the second step we show that small variations of endowments and utilities from those of $E$ will remain within the class of complex economies. This latter step uses Smale's (1974) results which establish that for a generic (open and dense) set of economies, the equilibrium allocations and prices depend locally continuously on the initial endowments and preferences. We construct a complex economy in steps.

Formally, let $\left(x_{s r}^{i *}\right)$ denote an equilibrium allocation in $E$ of an individual $h$ of type $i$ in individual state $s$ at a collective state $r$. If its $m$-component $\left(x_{s r}^{i *}-e_{s}^{i}\right)_{m}$ is negative, we say that $h$ is a net importer of $m$, or simply an importer of $m$, at this equilibrium. The same definition with the opposite sign applies to exporters of a good $m$. Similarly in $E^{*}$ individual $h$ of type $i$ is a net exporter of a good $m$ at the equilibrium allocation $\left(x^{i *}\right)$, when $\left(x_{s}^{i *}-e_{s}^{i}\right)_{m}>0$, where $x_{s}^{i *}$ is an equilibrium allocation for $E^{*}$. Let $r$ be a default state of the economy $E$ as defined in Section 3, and for $s, r$ let $h$ be an importer of good $m$ at an equilibrium allocation of $E,\left(z_{s r}^{i *}\right)$. Consider an equilibrium $\left(p^{*}, x_{s}^{i *}\right)$ of $E^{*}$, and an equilibrium allocation $\left(x_{s r}^{i *}\right)$ of $E$ in a state of insurance default $r \in \Gamma$.

An importer $h$ of good $m$ in economy $E$ is said to default at $s, r$ when the value of $h^{\prime} s$ net purchases of good $m$ at the default state $r \in \Gamma$ is lower than what $h$ contracted to purchase at the individual state $s$ in $E^{*}$, i.e. $\left|p_{m}^{*}\left(x_{s r}^{i *}(m)-e_{s}^{i}(m)\right)\right|<\left|p_{m}^{*}\left(x_{s}^{i *}(m)-e_{s}^{i}(m)\right)\right|$. A similar definition holds for exporters. Note that the values are given by the equilibrium price $p^{*}$ of the benchmark economy $E^{*}$.

First consider the case $N=H$. Let $E_{o}$ be an economy with $N$ goods, $H$ households, and equilibrium prices $p *$, where at the equilibrium allocation corresponding to $p *$, household 1 is the only net exporter of good 1 , and the only net importer of good 2 ; household 2 is the only net exporter of good 2 and the only net importer of good 3, etc., finally household $H$ is the only net exporter of good $N$, and the only net importer of good 1 . Note that $E_{o}$ is complex, for any default of any amount initiated by any of the households in any commodity $n=1, \ldots, H$. The argument is now extended to $N=H+b$, $b \leq H$. It suffices to modify $E_{o}$ as follows. Assume that household 1 is the only net exporter of goods 1 and $H+l$, and the only net importer of goods 2 and $H+2$; household 2 is the only net exporter of goods 2 and $H+2$; etc., household $b$ is the only net exporter of goods $b$ and $H+b$ and the only net importer of goods $b+l$ and 1 ; and finally household $H$ is the only exporter 
of good $H$ and importer of good $H+l$. The economy $E_{1}$ thus defined is clearly complex. Finally consider the general case of an economy $E$, where $N=a H+b, b<N$, for some $a \geq 0$. Define $i \bmod H$ as the set of all natural numbers $n>H$ such that $i$ is the remainder from dividing $n$ into $H$, i.e. such that $i$ satisfies $n=a H+i$, for some $a>0$. Then define the economy $E$ so that household 1 is the only net importer of all goods $1 \bmod H$ and the only net exporter of all goods $2 \bmod H$; household 2 is the only net exporter of all goods $2 \bmod H$ and importer of all goods $3 \bmod H$; etc.; finally $H$ is the only net exporter of all goods $0 \bmod H$ and net importer of all goods 1 $\bmod$ H. $E$ is clearly complex, see Figure 3.

The complex economy $\mathrm{F}$ of Theorem 2 . Household 1 is the only net importer of all goods 1 mod $\mathrm{H}$, and the only net exporter of all goods $2 \mathrm{mod}$ $\mathrm{H}$. There are $\mathrm{H}$ households and $\mathrm{N}$ goods, $\mathrm{N} \geq \mathrm{H}$.

Such an economy $E$ arises by assigning to household $i$ an endowment consisting exclusively of goods $i \bmod H$, a utility function with no utility for $\operatorname{good} i \bmod H$, and the sum of Cobb - Douglas utilities for goods $i+l \bmod$ H. Example 1 in Section 3 illustrates such an economy. Finally note that the complexity of $E$ survives small variations in net trades at the equilibrium. To see that the economy remains complex for small variations in net trades consider the following modification of the economy $E$. Consider first the case $N=H$. Assume that $p^{*}=(1, \ldots, 1)$ — this can always be assumed without loss of generality by changing the commodities' units of measurement. Now consumer 1 is no longer the only net importer of good 1 , but the main one: consumer 1 is a net importer of one unit of good 1 (in terms of the numeraire), while all other consumers together import less than $E$ at the equilibrium, $E<1 / 2 H$. Similarly consumer 1 is a net exporter of one unit of good 2, while all other consumers together export less than $1 / 2 H$ of good 2 , etc., until consumer $H$ who is a net importer of 1 unit of good 1, while the rest of all consumers import at most $1 / 2 H$ units of good $H$; and finally $H$ exports one unit of good 1, while all other consumers together export at most $1 / 2 \mathrm{H}$ units of good 1. Then any default of at least one unit of good $n, n=1, \ldots, H$, leads to default by all $H$ individuals. A small enough modification of endowments and preferences of produces another complex economy. The same argument can be employed to show that for small variations of endowments and utilities the economy $E$ with $N=a H+b, a>0, b<H$, remains complex. Therefore, $E$ may be modified so as to be within Smale's (1974) open and sense class of economies in which net trades vary (locally) continuously with initial endowments and utilities, and remain complex. Any further small modification will still remain within the class of complex economies, proving that there exists an open class of complex economies.

To prove that $k$ - complexity is an open property when $N>H$, construct an economy $E$ where $k$ individuals replicate economy $E_{o}$ of Theorem 1 , for $k$ 
goods. Assume all other individuals have zero net trades at the equilibrium $p *$. Then default can only be initiated by one of $k$ individuals, and leads to $k-1$ other defaults. This example is open since for any level of default $\delta>0$, we can modify the original economy so that the net trades of the households $h=k+1, \ldots, H$ add up to less than $\delta$. $\diamond$

Proof of Proposition 3:

This follows from Proposition 1 and the results of Section 3. In complex economies such as $E_{0}$ in Proposition 1, default always increases at least as a linear function of the population $H$, while the definition of individual risk is consistent with an arbitrary rate of convergence of the probabilities $\Pi_{H}$ as $H \rightarrow \infty$, as it requires only weak convergence of the probability measures $\Pi_{H} \rightarrow \Pi^{\infty}$, (see e.g. Malinvaud (1973), p. 387, para 4.) $\diamond$ 